\title{
Improving the performance and analyzing the mechanism of a gas cyclone with filtration
}

\author{
Zihui Zhang ${ }^{1}$, Sijie Dong ${ }^{1}$, Kejun Dong ${ }^{2}$, Li'an $\mathrm{Hou}^{3}$, Wenzheng Wang ${ }^{4}$, Yi Wei ${ }^{1}$, and Bo \\ Wang $^{1}$ \\ ${ }^{1}$ Lanzhou University \\ ${ }^{2}$ Western Sydney University \\ ${ }^{3}$ Xi'an High-Tech Institute \\ ${ }^{4}$ Gansu Chemical Industry Research Institute Co., Ltd
}

November 12, 2020

\begin{abstract}
This paper presents a study of the performance of a gas cyclone with a cylindrical filter face installed in the center from the vortex finder to the bottom hopper. The experimental results show that this composite cyclone can have a higher collection efficiency and a lower pressure drop than those of the gas cyclone. In addition, the outer vortex of the composite cyclone removes coarse particles and the filter can block fine particles outside the inner vortex, which will significantly increase the collection efficiency, especially for fine particles. The flow field of the composite cyclone is simulated by computational fluid dynamics with the Reynolds stress model to model turbulence and the porous media model for the filter. The result shows that the swirling disappears in the vortex finder and the kinetic energy dissipation lowers with the filter installed, which remarkably decreases the pressure drop.
\end{abstract}

\section{Hosted file}

Manuscript.pdf available at https://authorea.com/users/375031/articles/492417-improving-theperformance-and-analyzing-the-mechanism-of-a-gas-cyclone-with-filtration 


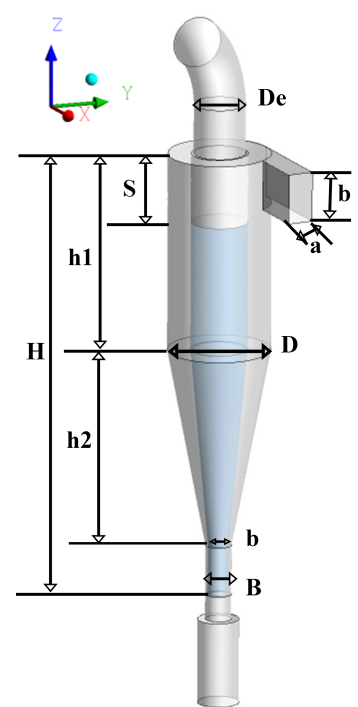

(a)

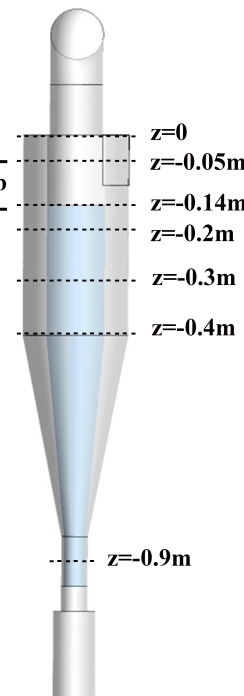

(b)

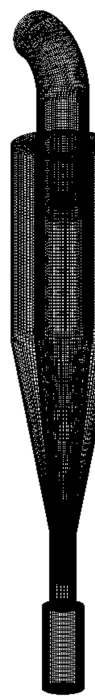

(c)

\begin{tabular}{cc}
\hline Parameters & Dimension(mm) \\
\hline Cylinder diameter (D) & 200 \\
Inlet height(b) & 100 \\
Inlet width(a) & 50 \\
Vortex finder diameter(De) & 100 \\
Vortex finder insertion depth(S) & 140 \\
Overall length(H) & 900 \\
Cylindrical length(h1) & 400 \\
Conical length(h2) & 400 \\
Duct diameter(B) & 50 \\
Bottom diameter of the thin \\
porous layer(b)
\end{tabular}

(d)

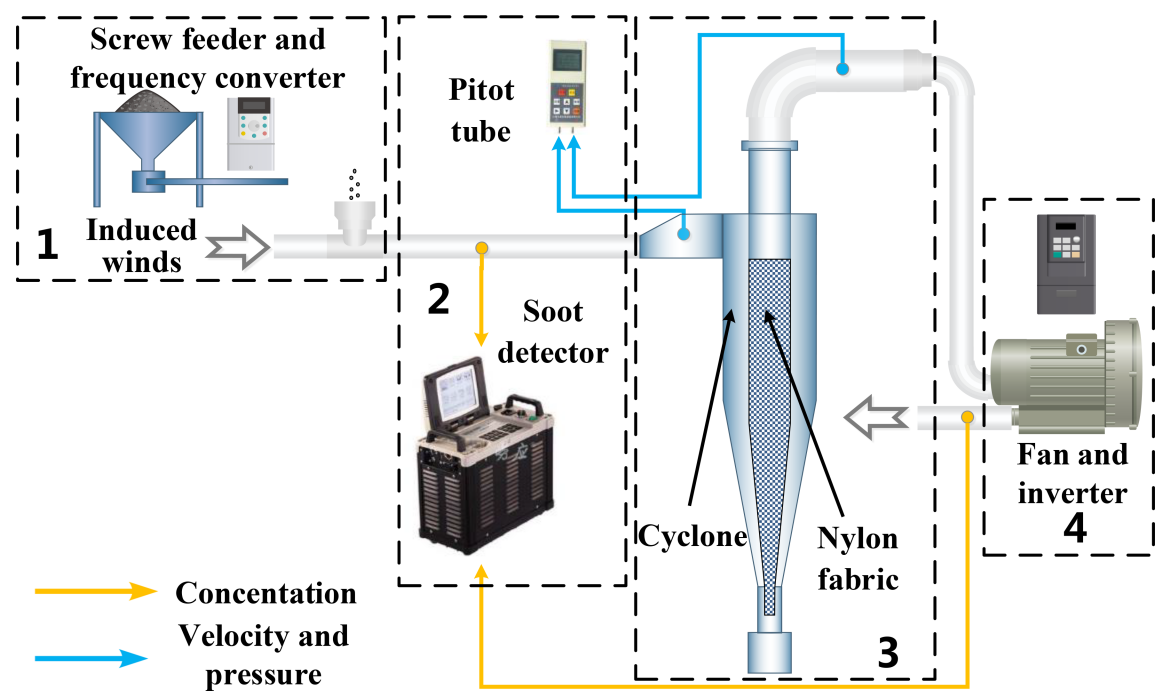

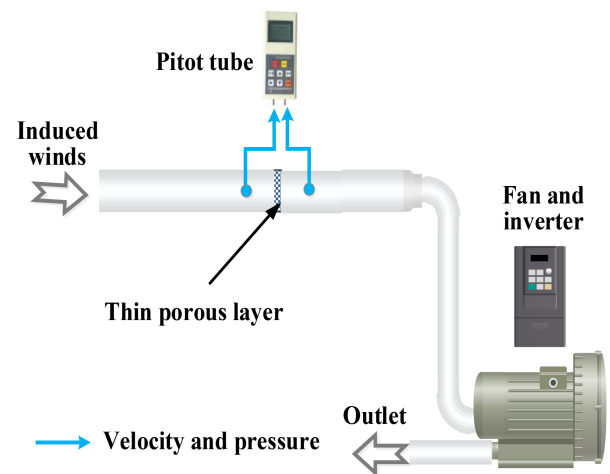

(a)

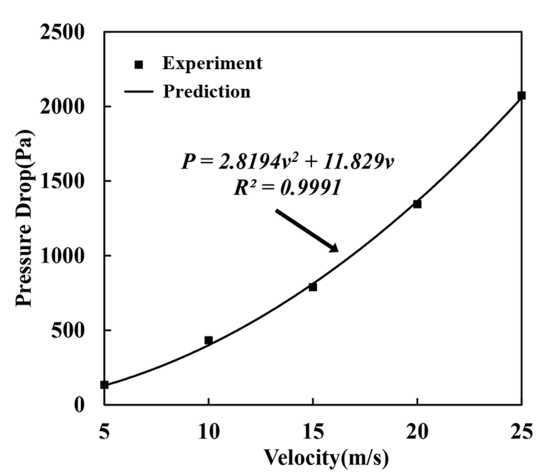

(b) 

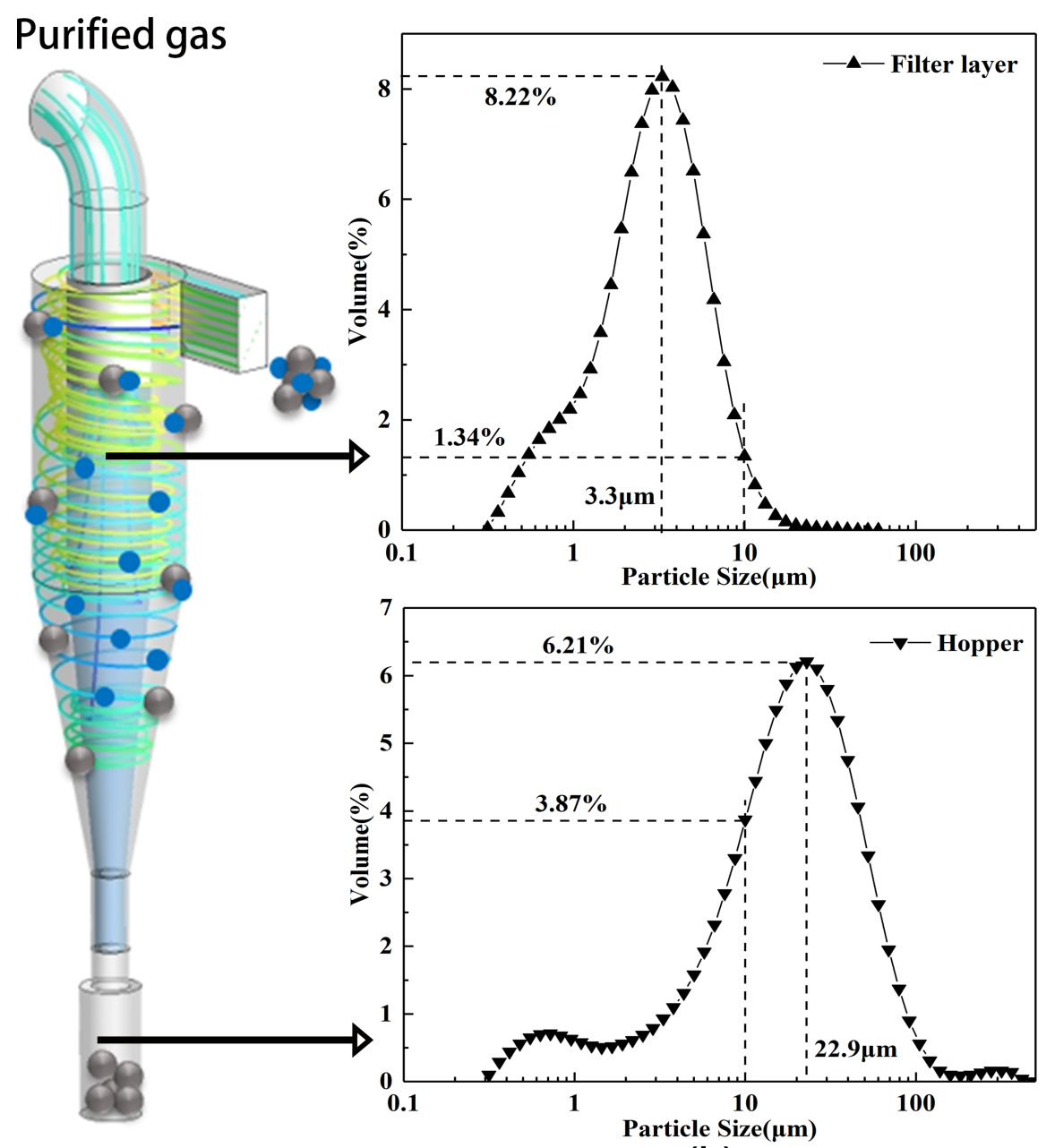

(a)

(b) 

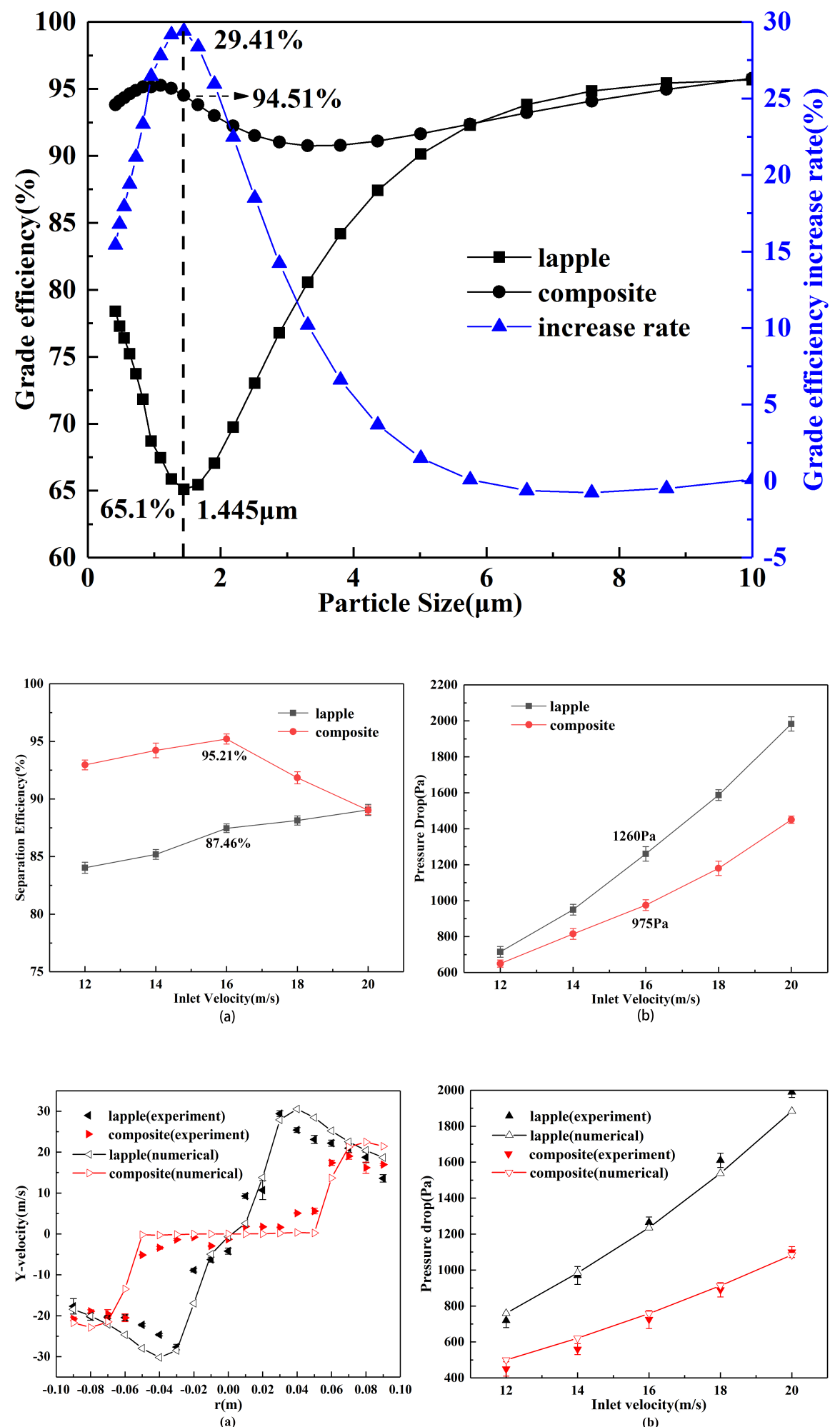




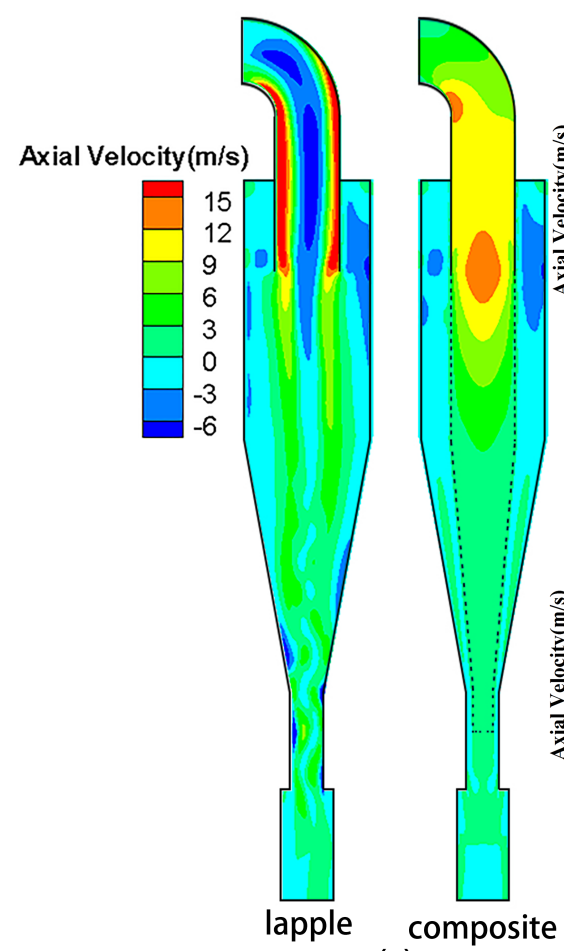

(a)
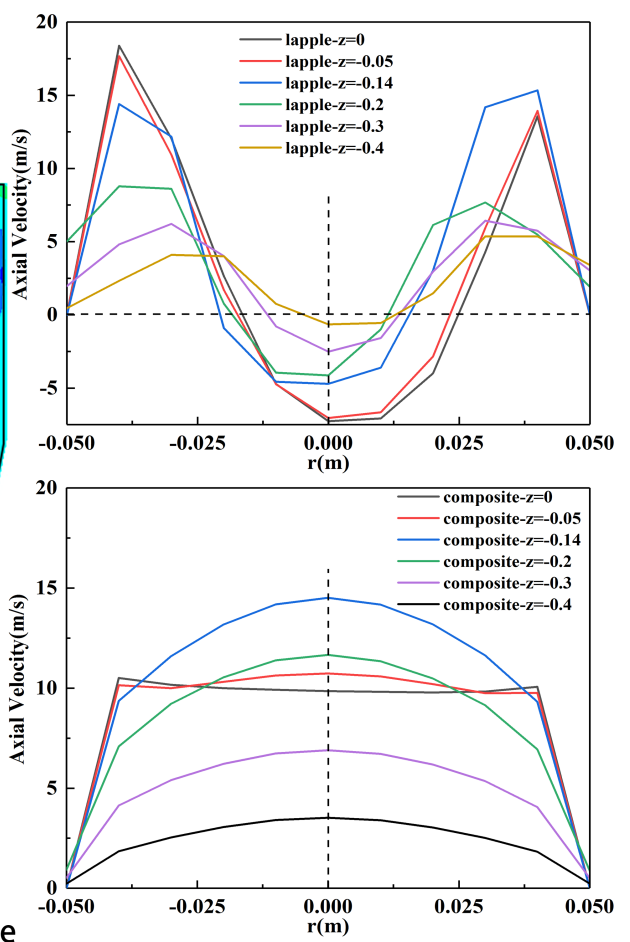

(b)

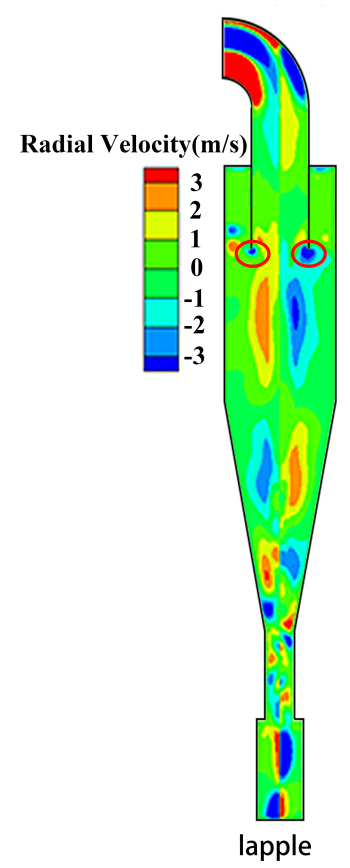

(a)

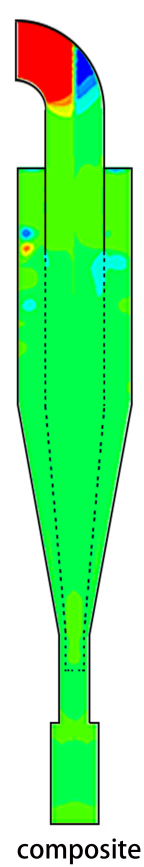

(a)

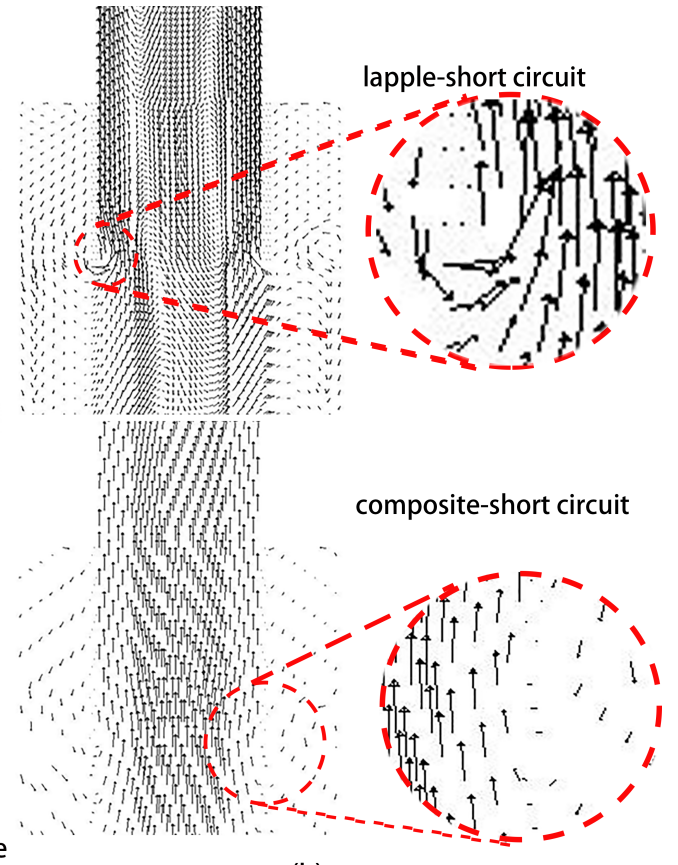

(b) 


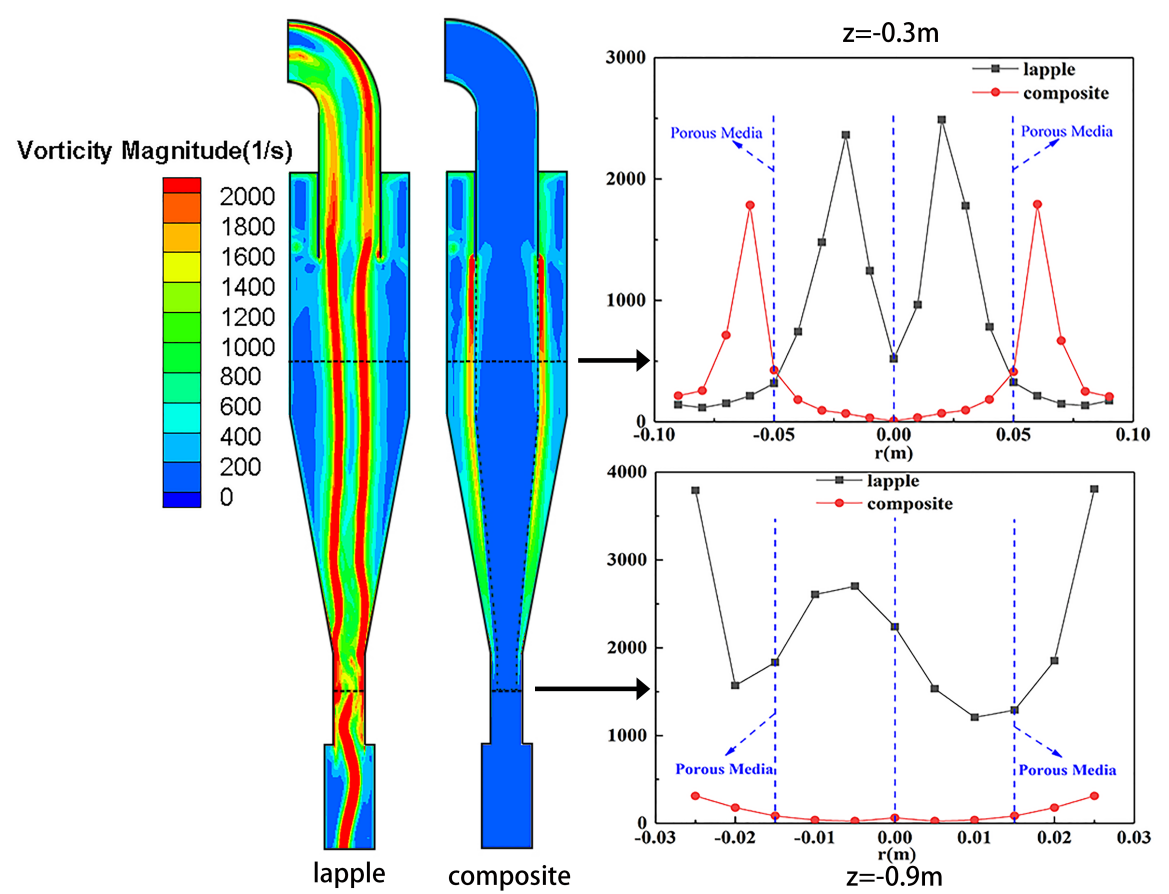

(a)

(b)

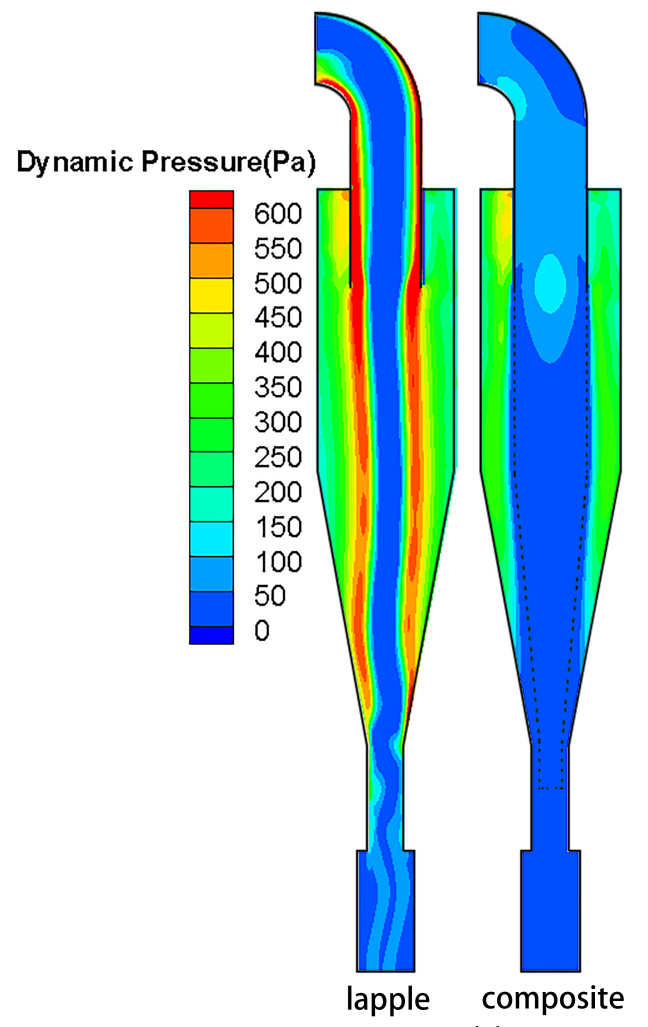

(a)

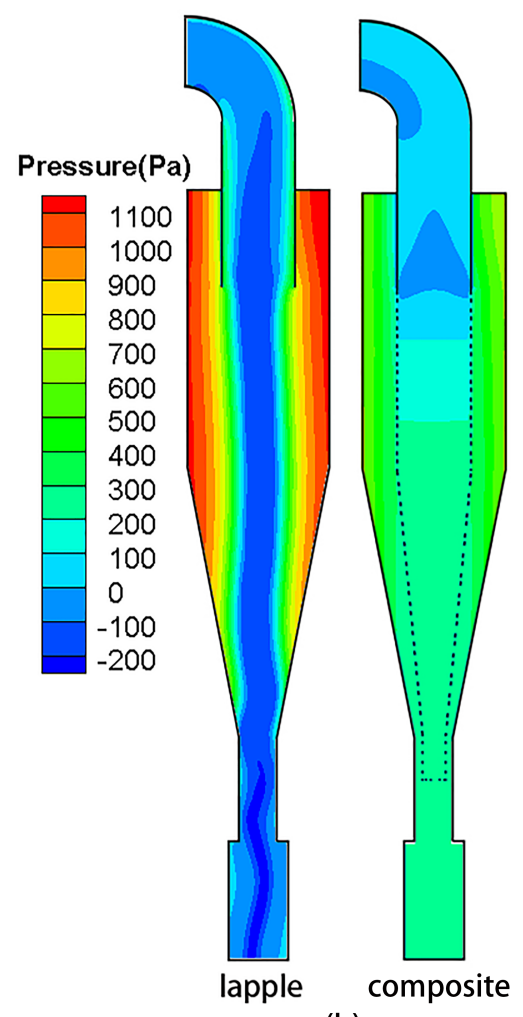

(b) 